\title{
Studies of the Possibilities of Determining the Degree of Erosion of Soils in Azerbaijan
}

\author{
Rae ZH Aliyev* \\ Institute of Erosion and Irrigation NAS of Azerbaijan, Azerbaijan
}

Received: 㘹 February 08, 2018; Published: 㘹 February 16, 2018

*Corresponding author: Rae ZH Aliyev, Institute of Erosion and Irrigation NAS of Azerbaijan, Azerbaijan

\begin{abstract}
The article examines the issues of the possibility of studying the areas of development by soil erosion and its control. The study proved that the development of soil erosion is based on the forming impact of natural and anthropogenic factors. The degree of potential danger and the possibility of prevention, taking into account the preservation of the environmental situation in the foothills of the Upper Shirvan in the example of the Shemakha district of the Republic of Azerbaijan, were studied. The main objectives of the study here was to determine the amount and degree of development of eroded and erosive dangerous soils of the foothill zones, carried out based on soil erosion surveys of the farms of the republic.
\end{abstract}

Keywords: Erosion soil; Assessment of the degree of erosion environmentally hazardous; Anti-erosion measures

\section{Introduction}

(Figure 1) According to the soil and climatic conditions of the territory of the Republic of Azerbaijan, it is divided into 10 economic zones-Absheron, Ganja-Kazakh, Kuba-Khachmaz, ShekiZagatala, Lenkoran, Aran, Upper Garabagh, Kelbajar-Lachin, Shirvan Mountain, Nakhichevan. These zones differ from each other not only in terms of geographical location and soil and climatic conditions, but also in terms of natural resources. It is known that from 11 basic climate type globe, in the Republic of them meets 9: a) dry subtropical, b) moist subtropical, c) semi-moist subtropical, d) dry continental, e) moderately warm, moist, f) moderately warm dry, g) moderately cold, h) cold, i) mountain tundra [1-3]. The territory of Azerbaijan is under the ecological impact of the catchment valley of the Caspian Sea. Here, environmental problems, the solution of which are regional and depend on interstate relations, and for this reason, day after day they become strained. It must be said that the country's soil is subject to erosion, forest plantations, mountain groves, water sources and other natural formations are failing. Geologically and geographically, the research region has a rather complex structure, where high mountains and steep slopes alternate with foothills and plains, which in turn contributes to the development of a fairly variegated climate, that is, to a variety of vegetation cover $[2,3]$.

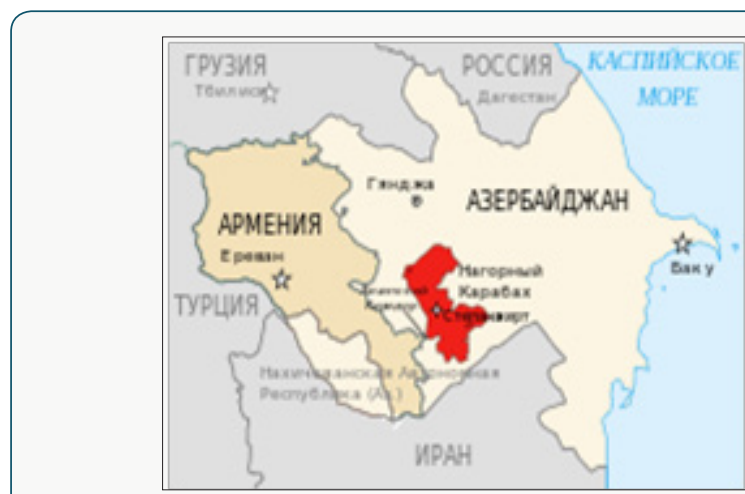

Figure 1:

\section{Object of the Study}

Defined in the example of Shemakha district of the foothills of the Shirvan Mountains zone. The study area is known as a zone of subtropical crops. The zone consists of lowland and mountainous parts. The most favorable conditions for the development of subtropical gardening are found in the low part of the zone. Part 
of the zone is drying subtropical, winter is mild, without snow and frost, and summers are dry and warm. Atmospheric precipitation ranges from 200 to $400 \mathrm{~mm}[2,3]$. In the territory under the zone are distributed brown, gray-earth, alluvial-meadow, meadow, serozemmeadow and other types of soils. In the described soil-climatic conditions, the pomegranate culture and all fruit crops, especially pome seeds, apple trees, grow well. In the forests there are wild forms of pear, apple, dogwood, medlar, etc. The complexity of the geomorphologic structure, the presence of steep slopes here, as well as the anthropogenic impact, exerts a significant importance to the intensity of surface runoff, which in turn intensifies the development of erosion processes, resulting in the creation of wide ravines, which in the final stage are represented by beams, altering the geomorphologic appearance of the area as a whole [4-6].

In general, according to the Shirvan zone, EM Shikhlinsky [7] distinguishes 3 types of climate:

i. Moderately warm, characteristic for the flat areas of the zone with a relatively mild winter.

ii. Moderately warm wet type with a uniform distribution of precipitation throughout the year, covers the foothills of the zone and

iii. Cold climate with humid winter, characteristic for the foothill and mountainous area of the zone.

The minimum air temperature is $0.5{ }^{\circ} \mathrm{C}$ in January, and the maximum temperature is at $23.6^{\circ} \mathrm{C}$ in July. The average monthly temperature of the soil varies within the limits of $-1{ }^{\circ} \mathrm{C}-30,7^{\circ} \mathrm{C}$. The minimum soil temperature in $-1{ }^{\circ} \mathrm{C}$ is in January, the maximum is $30,00 \mathrm{C}$ (July) and August is $30,7^{\circ} \mathrm{C}$ months. The annual precipitation is $692 \mathrm{~mm}$, the greatest amount of which falls in April-June months. The annual value of volatility is $825 \mathrm{~mm}$. The average annual relative air humidity is $71 \%$ fluctuating over the season from 59 to $87 \%$ [7].

\section{Objectives of the Study}

Is to study the results of monitoring studies to determine the degree of susceptibility of slope lands of the country and to develop prerequisites for its prevention.

\section{The Course of Research and Discussion of the Results}

Itshould be recognized that the results of numerous fundamental and applied research on the development of soil erosion and erosion measures have shown that the study of the problem by modern methods is inevitable and naturally it has always been practiced, but it should be noted that with the use of new works of the abovementioned subjects, experimental and applied research in this field of science, where solutions were sought to prevent it through a comprehensive approach and solving the problem of studies on the development of areas of erosion process. It is known that a far from complete list of information on erosion of soils and measures to combat it at different administrative and economic levels go beyond their visual and other reports of researchers and university textbooks and can provide significant assistance to authors in solving many scientific and applied problems, which could not be fully resolved to the present time in the republic. The direction of research on the topic of soil erosion, mapping and erosion control design, recommended to students, is wide and diverse, and can be proposed by the main blocks (directions) of research: soil erosion - terminology, classifications; conditions that determine the danger of erosion; assessment and mapping of erosion hazardous land; mapping of washed-away soils; protection of soils from erosion; design of anti-erosion measures; ecological, social and economic effectiveness of anti-erosion measures; the state of scientific research on the problem of soil protection from erosion in Azerbaijan and other countries of the world [2]. Natural and climatic conditions of the republic due to the lack of water balance contribute to the development of both erosion and deflation, which requires special, progressive methods of developing soil cultivation, cultivation, melioration and protection of the already small land fund.

It should be noted that in the country the main arrays of lands suitable for irrigated agricultural use already amounting to 1.410 million hectares have been developed and further expansion of arable land is possible only due to the development of less productive lands, which requires excessive protection from soil erosion on the developed lands, their fertility is of great importance for the country. In the process of realization of scientific researches carried out by the authors at the Institute of Erosion and Irrigation of ANAS in this field of research in their monographs soil erosion is presented as a function of natural and anthropogenic factors and its ecological consequences. The authors proceeded from the assumption that each science requires certain precision and clarity of concepts, and as the new results are achieved, the measures of struggle and the classification of the objects under study are continuously improved [2,6]. Many scientists were involved in these issues, for example: Zavaritsky AN (1947), Sobolev SS (1948), KA Alekperov (1950-1970), Khalilov MH (1972-1989), Ibragimov AA (1967-2010), Shvebs GI (1977), Belbibaev ME (1970), Budagov AA (1953-2006), Aliev BP (1990-2016), Zaslavsky MN (1972-1979), etc.), in the works of which the terms derived from the word erosion as well as the concepts of water and wind erosion were treated very widely and not always definitely, and in this connection, many examples of contradictory their interpretation. Among the authors of the published monographs, MN Zaslavsky, KA Alekperov and BH Aliyev are the closest to the authors who, instead of the widely used term, water erosion recommends the use of the term soil erosion to denote both flushing and soil erosion by surface runoff temporary water currents, and the term deflation (wind blowing) instead of wind erosion, which accurately reflects the essence of the phenomenon. The scales and geography of soil degradation in the reporting materials and the authors' monographs, the economic damage from erosion are appalling. The significant structural changes implemented as a result of land reforms in agriculture 
started in Azerbaijan since 1990 led to a reduction in the area of agricultural land, the removal from agricultural use of vast areas of arable land and forage lands affected by degradation, enormous economic and environmental damage and the threat to subsistence soil as the main means of production and an indispensable component of the biosphere.

It is known that the regularities of the manifestation of soil degradation are associated with natural and climatic, lithologicgeomorphological features, as well as the intensity of manifestation of anthropogenic influence [1,3,8]. The Azerbaijan Republic, despite its inadequate study, is characterized by considerable areas of arable land with a very low content of humus, high acidity, and a deficiency in the phosphate regime of soils. The results of this study determined that in Azerbaijan slope lands occupy 3236 thousand hectares. The distribution of land in the natural and economic zones of the republic by relief conditions is located as follows (Table 1). Thus, the limited land resources force to plow even steep slopes. It is assumed that the slopes from 30 to 150 (slopes 0.05-0.25) are sloping, from 150 to 200 (0.25-0.35) transient to steep, 200-steep. Based on the results of studies and other scientists, it is believed that 216 thousand hectares are located on steep slopes from the given boundary of inclines, from suitable for irrigation, 629 thousand hectares in areas with slopes from 0.05 to 0.20 , ha-on flat sections with gradients 0.05 . According to the conclusion on the slopes 15200 it is necessary to place gardens and vineyards. Often, slopes of $30-40^{\circ}$ and more degrees are used for vineyards with the direction of rows along the slope, which creates the most difficult conditions for the operation of agricultural machines and enhanced flushing of the upper fertile soil layer in the inter-row spacing. Therefore, the author believes when laying new gardens and vineyards, one should not go on an apparently more economical way of laying in the direction of the slope. There is also the use of steep slopes for sowing grain and forage crops. Plowing and tillage in such areas are carried out along the slope, which contributes to the increase of soil washout and a sharp decrease in its fertility. Many years of systematic, unjustified use of chemical plant protection products in the region, both years of Soviet power, and now especially of pesticides, is one of the main problems in the agricultural zone of the republic as Guba-Khachmas, Ganja-Gazakh, Shirvan Mountains and Garabagh. Pollution here soil adversely affects plants, reduce crop yields and loss of potential soil fertility. Along with the pollution of ecosystems, it has negative consequences for the population and livestock in the region $[2,3,6]$.

Table 1: Distribution of land in natural and economic zones of the republic by relief conditions.

\begin{tabular}{|c|c|c|c|c|c|}
\hline \multirow{2}{*}{$\begin{array}{l}\text { Natural and } \\
\text { economic zones }\end{array}$} & \multirow{2}{*}{$\begin{array}{l}\text { Suitable for } \\
\text { irrigation, land on } \\
\text { relief conditions }\end{array}$} & \multicolumn{4}{|c|}{ Including with slopes } \\
\hline & & $<0,05$ & $0,05+0,10$ & $0,10+0,20$ & $0,20+0,40$ \\
\hline 1 & 2 & 3 & 4 & 5 & 6 \\
\hline Ganja-Kazakh & 427,50 & 251,0 & 72,8 & 63,70 & 40,00 \\
\hline Shirvanaya & 680,80 & 522,6 & 50,0 & 66,10 & 42,10 \\
\hline Karabakh-Mila & 749,00 & 567,6 & 80,20 & 47,40 & 53,80 \\
\hline Mugano-Salyan & 429,8 & 402,4 & 2,8 & 17,1 & 7,5 \\
\hline Sheki- Zakatal'skaya & 322,7 & 236,5 & 42,7 & 23,8 & 19,7 \\
\hline Lankoran & 81,5 & 79,5 & 2,0 & - & - \\
\hline Absheron & 52,7 & 31,1 & 21,6 & - & - \\
\hline Cuba-Hachmazskaya & 203,5 & 179,1 & 24,4 & - & - \\
\hline Upper Karabakh & 133,7 & 24,7 & 27,8 & 37,6 & 43,4 \\
\hline Nahiçevanskaya & 154,2 & 95,3 & 38,0 & 11,2 & 9,7 \\
\hline $\begin{array}{l}\text { TOTAL in the } \\
\text { republic }\end{array}$ & 3235,4 & 2390,0 & 362,3 & 266,9 & 216,2 \\
\hline
\end{tabular}

Pollution of the environment has become one of the most important tasks of our time; a special role belongs to heavy metals, which have the ability to accumulate in soils and through them to enter food products, while contributing to soil degradation. The zoning of the territory of the republic on irrigation techniques and the degree of erosion of soils in the republics has shown that the 14 regions of the republic surveyed by us have a tense situation in which there is a risk of withdrawal of arable land here because of intensive use due to complete soil degradation (Table 2). In Azerbaijan, there are all types of erosion (including water, mudflow, wind, surface, linear, etc.). Examples are visible from the map of the threat from potential surface erosion in the territory of the Shemakha district
(Figure 2). It should be recognized that due to the increased planar erosion here, the washing of the soil from ha amounted to more than 9.0 tons. As our studies have shown, when restoring the vegetation cover and increasing the productivity of eroded soils, immediate and timely planting of herbs is essential. Referring to the results of our experiments conducted in 2010-2012 in the region, we recommend carrying out sowing of grass mixtures in the autumn. As can be seen from the table, the most common is water erosion, which is developing more intensively in mountain regions. Soil soils in this and other extent are subject to erosion, which covers 51.0$92.4 \%$ of the land area. In the Shahbuz and Ordubad regions, the soils were strongly eroded and, correspondingly, 54.3 and $67.2 \%$ 
$[2,6]$. Here it is possible to increase irrigated land to 1235 hectares. The mountain areas mentioned above, due to the collection of mudflows into small bodies of water, more than 1300 hectares wet or unsustainable soil conduct irrigation, which serves to protect mudflow and irrigation erosion in these areas. In addition, by reducing soil erosion, introducing a number of measures, including providing enough soil with mineral fertilizers in these areas, production of 35.0 thousand tons of wheat, 12.0 thousand tones of tobacco, and 10-15 thousand tones of tobacco can be achieved. Tons of vegetables, 95-100 thousand tons of potatoes, and also due to the improvement of the forage base, significantly increase the production of livestock products $[2,3,6]$.

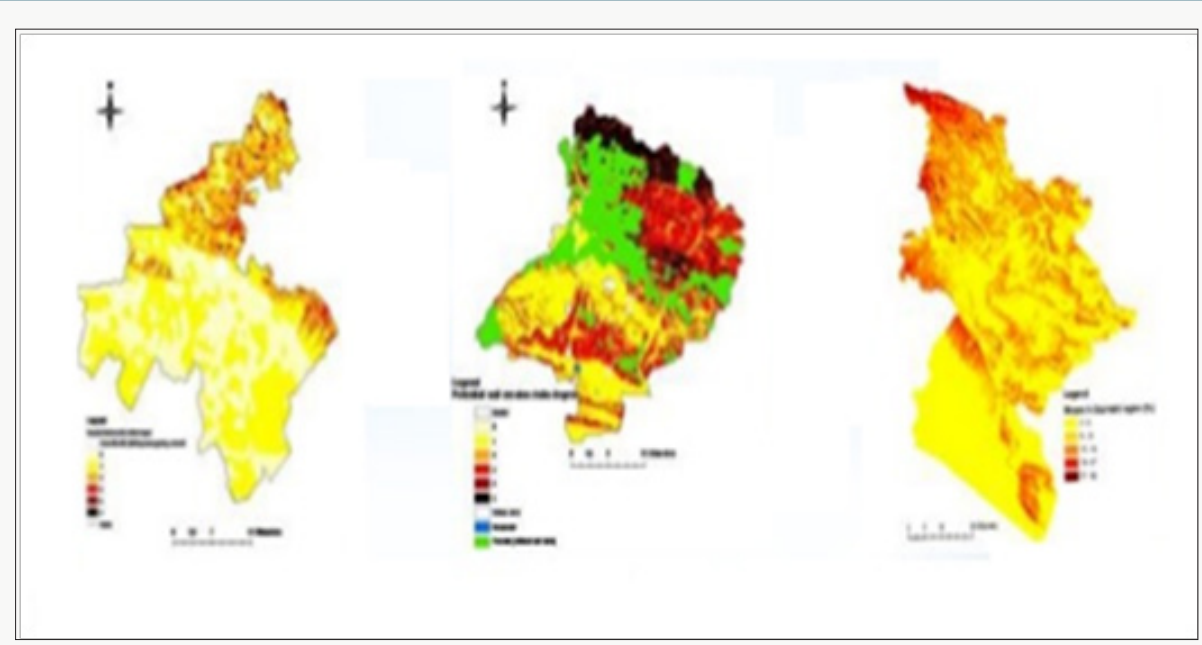

Figure 2: Threats from potential surface water erosion of the foothills of the upper Shirvan in the example of Shamakhi district.

Table 2: Exposure to soil erosion in mountainous regions of Azerbaijan.

\begin{tabular}{|c|c|c|c|c|c|}
\hline \multirow[b]{2}{*}{ Areas } & \multirow{2}{*}{$\begin{array}{l}\text { Total area in } \\
\text { thousand hectares }\end{array}$} & \multicolumn{4}{|c|}{ Including the degree of susceptibility to erosion } \\
\hline & & $\begin{array}{c}\text { Not subject thousand } \\
\text { hectares, } \%\end{array}$ & Few & medium & strong \\
\hline Dashkesen & 90,3 & $23,3 / 25,8$ & $18,3 / 20,3$ & $25,6 / 28,3$ & $23,1 / 25,6$ \\
\hline Kedabek & 150,3 & $73,6 / 49,0$ & $20,1 / 13,4$ & $29,8 \backslash 29,8$ & $26,8 / 27,8$ \\
\hline Kelbajar & 124,3 & $48,4 / 38,9$ & $27,2 / 21,9$ & $18,9 / 15,2$ & $29,8 / 24,0$ \\
\hline Lacin & 166,5 & $56,7 / 34,1$ & $26,3 / 15,8$ & $36,7 / 22,0$ & $46,8 / 28,1$ \\
\hline Kubadly & 79,8 & $25,7 / 33,5$ & $6,9 / 8,6$ & $28,7 / 36,0$ & $17,5 / 21,9$ \\
\hline Node & 72,5 & $24,6 / 33,9$ & $16,4 / 22,6$ & $14,6 / 20,2$ & $16,9 / 23,3$ \\
\hline Lerik & 136,5 & $43,6 / 32,2$ & $19,4 / 14,3$ & $27,8 / 20,5$ & $44,7 / 33,0$ \\
\hline Yardimli & 12,5 & $25,1 / 34,6$ & $12,6 / 17,4$ & $10,6 / 14,6$ & $24,2 / 34,4$ \\
\hline $\begin{array}{l}\text { Mountain part } \\
\text { Goranboy }\end{array}$ & $57,6 / 20,8 / 19,5$ & $7,7 / 36,1$ & 33,9 & 13,4 & $9,6 / 16,6$ \\
\hline Julfa & 99,4 & $9,9 / 10,0$ & $16,3 / 16,4$ & $25,3 / 25,5$ & $47,9 / 48,1$ \\
\hline Cheaper & 81,4 & $61,1 / 19,8$ & $5,4 / 6,6$ & $15,7 / 19,3$ & $14,2 / 54,3$ \\
\hline Ordubad & 92,4 & $7,0 / 7,6$ & $9,5 / 10,6$ & $13,5 / 14,6$ & $62,1 / 67,2$ \\
\hline Apșeron & 535 & $57,5 / 10,7$ & $116,8 / 21,8$ & $165,5 / 30,9$ & $195,5 / 36,6$ \\
\hline
\end{tabular}

On the development of mountain and foothill regions on the sloping lands of Azerbaijan with the use of newly developed irrigation equipment, we carried out a large volume of long-term research work under the direction of BG Aliyev [2]. Given the above, it is recommended for the mountain and foothill areas the following methods of watering

a) On furrows with a slit

b) Sprinkling with low intensity of rain c) Finely dispersed moistening in combination and without combination with sprinkling

d) Drip irrigation, and others.

Watering on furrows with a slit of terrain $<0,03$ except for garden for all other crops under the conditions in question, the surface watering method is not recommended because of uneconomical water consumption. It should be noted that the creation and development of new progressive irrigation methods 
is an exception to irrigation erosion, saving irrigation water and not violating environmental protection of the environment. It follows from the foregoing that when developing mountain slopes not only in Azerbaijan but also in the countries of the world, a cautious approach is required to properly select the technique and technology of irrigation recommended for irrigation of tilled crops on lands with slopes. According to the conclusion on the slopes 15200 it is necessary to place gardens and vineyards. Often, slopes of 30-400 and more degrees are used for vineyards with the direction of rows along the slope, which creates the most difficult conditions for the operation of agricultural machines and enhanced flushing of the upper fertile soil layer in the inter-row spacing. Therefore, it is preferred that when laying new gardens and vineyards, one should not go on the seemingly more economical way of bookmarking in the direction of the slope. There is also the use of steep slopes for sowing grain and forage crops $[1,2,6]$. At the same time, it should be recognized that the effectiveness of the anti-erosion measures developed by us and the prevention of the erosion risk is a complex of protective agents that contributes to the regulation of surface runoff, protection of soils from flushing, erosion, and at the same time, the restoration and increase of the fertility of the washed out soil and the involvement of washed-away lands in rational use in the agricultural sector of the republic [9].

\section{Conclusion}

To solve the task, it is necessary to differentiate the land according to its natural potential and the degree of erosion with the subsequent definition of a set of measures to stop the processes of degradation and restoration of soil fertility with subsequent zoning of the territory of the republic according to the degree of erosion, with obligatory consideration of all factors affecting the condition and use of land in different types of soils of the republic.

\section{References}

1. Aliev GA (1978) Soils of the Greater Caucasus within the Azerbaijan SSR. Baku Elm p.157.

2. Aliev BG, Aliev ZG Aliyev (2000) In Problems of erosion in Azerbaijan and ways of its solution. Publishing house Ziya CPI Nurlan Baku, Azerbaijan.

3. Babaev MP, AM Djafarov (2017) The Modern Wounded Cover of the Greater Caucasus. Baku, Azerbaijan.

4. (2007) Biodiversity and climate diversity.

5. Vernadsky VI (1908) Works on the general history of science. In VI Vernadsky, Moscow, Russia.

6. Mamedov GSh (2000) Land reform in Azerbaijan legal and scientificenvironmental issues. Baku, Azerbaijan, p.371.

7. Mamedov RG (1970) Agrophysical characteristics of soils near the Araxian strip. Baku, Azerbaijan, p. 321.

8. Flint VE (2002) Conservation and restoration of biodiversity. Moscow Izd Scientific and educational methodical center p. 282.

9. Shikhlinsky EM (1968) The climate of Azerbaijan, Baku, Azerbaijan. 341 p.
CC (i) This work is licensed under Creative

To Submit Your Article Click Here: Submit Article Commons Attribution 4.0 License

DOI: $10.32474 /$ CIACR.2018.01.000108

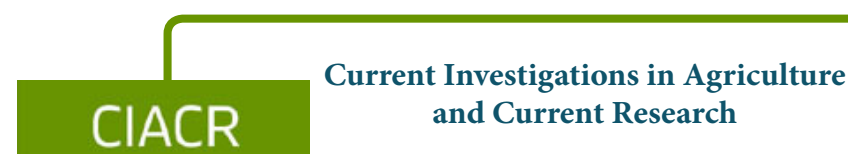

Assets of Publishing with us

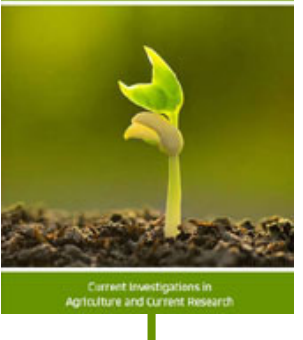

- Global archiving of articles

- Immediate, unrestricted online access

- Rigorous Peer Review Process

- Authors Retain Copyrights

- Unique DOI for all articles 